Article

\title{
Correlates of Alcohol Consumption Among a Socially-Disadvantaged Population in Poland
}

\author{
Kinga Polanska * and Dorota Kaleta \\ Department of Hygiene and Epidemiology, Medical University of Lodz, 90-752 Lodz, Poland; dkaleta@op.pl \\ * Correspondence: kinga.polanska@umed.lodz.pl; Tel.: +48-42-272-52-88
}

Received: 6 October 2020; Accepted: 2 December 2020; Published: 4 December 2020

\begin{abstract}
Alcohol consumption at a level exceeding existing recommendations is one of the leading risk factors for death and disability worldwide. The aim of the study was to identify correlates of alcohol drinking among a socially-disadvantaged population in Poland. The cross-sectional study covered 1644 adult social assistance beneficiaries from the Piotrkowski district (rural area in central Poland). A detailed questionnaire filled in during a face-to-face interview allowed for the collection of socio-demographic, lifestyle-related (including alcohol consumption) and health status data. About $42 \%$ of the participants, including $67 \%$ of the men and $30 \%$ of the women, exceeded the recommended level of alcohol consumption. In the adjusted model, the men tended not to follow recommendations for alcohol consumption more frequently than the women ( $\mathrm{OR}=4.5, p<0.001)$. The higher odds of not following alcohol-related recommendations were also observed for the subjects declaring having a permanent or temporary job compared to the unemployed participants $(\mathrm{OR}=1.2, p=0.04)$. A lower healthy lifestyle index (indicating an unhealthy lifestyle related to a diet, body mass index (BMI), physical activity, and tobacco smoking) was associated with not following recommendations for alcohol consumption ( $\mathrm{OR}=1.1, p=0.04)$. Our study indicates that being men, having a permanent or a temporary job, and coexistence of other unfavorable lifestyle-related factors are important correlates of not following recommendations for alcohol consumption among the beneficiaries of government welfare assistance.
\end{abstract}

Keywords: inequalities; alcohol consumption; lifestyle factors; healthy lifestyle index; correlates; socially-disadvantaged population

\section{Introduction}

Alcohol use is recognized as an important determinant of health. Reducing alcohol drinking might aid in achieving some of the 17 Sustainable Development Goals (SDG) adopted by all United Nations Member States in 2015, including those focusing on maternal and child health, non-communicable diseases (NCD), infectious diseases as well as mental health, injuries, and poisonings [1-4]. Alcohol consumption is also shown as one of the indicators for the SDG health target 3.5- "Strengthen the prevention and treatment of substance abuse, including narcotic drug abuse and harmful use of alcohol" [2].

In 2016, about 2.3 billion people (43\%) of the global population aged 15 and older were current drinkers [3]. Moreover, the highest levels of alcohol consumption are still observed in the countries of the World Health Organization (WHO) European Region. According to the WHO Global Health Observatory in 2015-2017 period, in Poland, the average total (recorded and unrecorded) alcohol consumption was $11.6 \mathrm{~L}$ of pure alcohol per person aged 15 or over, and it was $0.2 \mathrm{~L}$ more than during the 2009-2011 period [3].

Alcohol drinking contributed to 3 million deaths (5.3\% of all deaths) worldwide and 132.6 million (5.1\%) disability-adjusted life years (DALYs), including 2.3 million deaths and 106.5 million DALYs 
among men [3]. Of all alcohol-related deaths, about one-third was due to injuries, which is the same proportion due to cardiovascular diseases or cancers, one-fifth due to digestive diseases, and $13 \%$ due to infectious diseases. About one-half of alcohol-attributable DALYs were due to NCD and mental health conditions. It needs to be pointed out that the proportions of all deaths and DALYs attributable to alcohol consumption were also the highest in the WHO European Region $(10.1 \%$ of all deaths and $10.8 \%$ of all DALYs) [3].

Numerous studies have confirmed that lifestyle-related behaviour, health, and well-being are influenced by individuals' socio-economic factors. Although, in recent years, improvement in living standards have been observed in the majority of the developed countries, while disparities between or within a country are still widening $[1,5,6]$. Education, employment, and income are the most frequently pointed out determinants related to socio-economic status (SES) that can influence both patterns of alcohol consumption and their health-related harm. This has been confirmed by the literature reviews, which indicate complex, multifaceted relationships between social determinants, inequities, and alcohol consumption [5,6], on one hand, and the role of alcohol use and drinking patterns in socio-economic inequalities in mortality, on the other hand [1,7-9]. However, individuals with a higher SES may consume similar or greater amounts of alcohol compared to those with a lower SES. The latter group seems to bear a disproportionate burden of negative alcohol-related consequences [1,7-11]. This phenomenon can result from the fact that other lifestyle-related factors such as tobacco smoking or obesity cluster in individuals with a low SES and interact with alcohol use, resulting in elevated risks related to alcohol use in this group [12]. Access to healthcare services as well as variations in drinking patterns are additional potential factors contributing to the exacerbated health consequences of alcohol use among individuals with a low SES [13,14].

Taking into account the above considerations, understanding the correlations between the variety of socio-demographic and lifestyle-related factors and alcohol consumption among people representing an unfavorable economic situation is critically important for identification and development of effective interventions. To the best of our knowledge, such comprehensive analyses have not been performed among such vulnerable populations in Poland. Thus, the aim of this study was to evaluate the correlates of not following recommendations for alcohol drinking among social assistance beneficiaries from a socio-economically disadvantaged rural area in Poland.

\section{Material and Methods}

\subsection{Study Design and Population}

The series of analyses, including correlates of tobacco smoking, diet, and recreational physical activity among socially-disadvantaged adults (18-59 years) from the Piotrkowski district (central Poland) have been already published [15-17]. According to the data from 2013, there were 91,618 residents living on the premises of the district with more than $90 \%$ of them representing rural areas. Approximately $9 \%$ of its residents required the support of social assistance institutions due to the lack of resources to live on. An analysis completed by the United Nations Development Program (UNDP) identified the district as the 11th among all 314 rural districts with the lowest indicators of social development in Poland. The Local Human Development Index (LHDI), covering three indicators: Health Index, Education Index, and Welfare Index, was one of the lowest in the country [15-17].

Our cross-sectional study covered residents of the Piotrkowski District registered with the local government welfare assistance institutions and entitled to receive social aid. The poverty threshold (a monthly income equal to or less than 634 PLN (148 Euro) for a single person or 514 PLN (120 Euro) for a family member) has been used by the social assistance institutions to ensure social aid according to the regulations specified in The Social Welfare Act $[18,19]$. This poverty threshold is approximately $50 \%$ of the minimal net salary. Following the inclusion criteria (age and income restrictions), 3636 people were eligible for the study, 1817 (50.0\%) individuals agreed to participate in the study, and 1644 participants 
( $90 \%$ of those who filled in the questionnaire) provided data about alcohol consumption crucial for the current analyses.

The study was approved by the Bioethics Committee of the Medical University in Lodz (RNN/243/15/KE).

\subsection{Alcohol Consumption}

The detailed information on alcohol consumption was obtained using a questionnaire that was filled in during an interview conducted by trained staff at the place of residence of each participant. The respondents declared frequency (never, rather than once per month, average times per month, average times per week, everyday) and intensity (average volumes of alcohol per one occasion) for each type of drunk alcohol (spirit, beer, and wine). Based on this information, a unit of alcohol per occasion and per week was calculated following the formula: unit of alcohol $=($ volume $(\mathrm{ml}) \times$ abv $) / 1000$. The participants were also asked about the frequency of binge drinking described as five or more drinks of alcohol on one occasion (never, rare (1-2 times per year), once per month, once per week, few times per week). It is proven by the existing research that frequent and high-quantity alcohol consumption (exceeding daily and weekly limit and binge drinking) is related to a poorer health-related quality of life $[3,20,21]$. The following three recommendations were considered: 1) daily limit—not more than $40 \mathrm{~g}$ of pure alcohol for men (4 units) and $20 \mathrm{~g}$ of pure alcohol for women ( 2 units), 2) weekly limit—not more than $210 \mathrm{~g}$ of pure alcohol for men (21 units) and $140 \mathrm{~g}$ of pure alcohol for women (14 units), and 3) no binge drinking (5 or more drinks per occasion at least once per month). Thus, a participant was defined as following alcohol-related recommendations if all of the three previously indicated recommendations were followed.

\subsection{Corelates of Alcohol Consumption}

As described previously, information about socio-demographic and lifestyle characteristics as well as health status of the participants was collected by using the detailed questionnaire [15-17,22]. The following socio-demographic variables were selected for the current study: the participants' sex, age, educational level, employment status, subjective assessment of monthly income, living conditions and life satisfaction, cohabitation status, and presence of children below 15 years of age in the household. The participants were also asked several questions dedicated to the following lifestyle-related characteristics: smoking, height and weight, diet, and recreational physical activity. The current smoking status was evaluated based on a question "Are you currently smoking cigarettes?" (the participants who answered "no" were classified as following smoking-related recommendations) [22]. Based on height $(\mathrm{m})$ and weight $(\mathrm{kg})$, body mass index (BMI) $\left(\mathrm{kg} / \mathrm{m}^{2}\right)$ was calculated. Healthy weight was defined as BMI between 18.5 and $24.9\left(\mathrm{~kg} / \mathrm{m}^{2}\right)$ (thus, the participants were considered as following BMI-related recommendations) [23]. The study participants reported the frequency of fruit and vegetable consumption. The individuals who consumed eight or more combined servings of fruits and vegetables per day were considered as following diet-related recommendations [24]. Finally, the study subjects were asked to indicate frequency (per week), intensity (moderate-intensity physical activity and vigorous-intensity physical activity), and length (minutes per day) of recreational physical activity. It is recommended that adults participate in 150 minutes per week of moderate-intensity physical activity, 75 minutes per week of vigorous-intensity physical activity, or 115 minutes of combined-intensity physical activity per week [25]. The participants who achieved at least one of the previously mentioned criteria for the recommended level of recreational physical activity were coded as following recommendations related to recreational physical activity.

As described by Znyk et al., 2020, for each of the four lifestyle-related characteristics (smoking, BMI, diet, and recreational physical activity), the participants could receive 1 if they followed the relevant recommendations and 0 if the recommendations were not followed [22]. Based on this data, the combined healthy lifestyle index (HLI) was calculated as the sum of points given for each of the four lifestyle-related factors. This index can range from 0 to 4 , were 4 means that a participant follows 
all the analyzed lifestyle-related recommendations. The participants' health status was evaluated using two questions: "How can you describe your health state?" (with the following possible answers: fair, rather fair, neither fair nor poor, rather poor, poor) and "Have you noted the following health problems within the past month?" (with yes/no option for the following health problems: chest pain, joint pain, back pain, headache, insomnia, severe depression, hypertension, gastrointestinal problems, other-please specify).

\subsection{Statistical Analysis}

For the variables included in the study, the numbers and percentages (as a proportion of the study sample or selected category) were presented.

The analysis of not following recommendations for alcohol consumption by socio-demographic and lifestyle-related characteristics of the population was performed. The unadjusted and adjusted odds ratios (OR), 95\% confidence intervals ( $95 \% \mathrm{CI}$ ), and $p$-values were calculated. The multivariable logistic regression was performed with the inclusion of all of the studied variables with $p$-values below 0.1 in the univariable analyses. The analyses stratified by gender were also presented in Supplementary Materials. The standard significance level $p<0.05$ was selected for the interpretation of the results. STATISTICA version 10.0 (Dell Software, Arizona, CA, USA) was used to perform the statistical analysis.

\section{Results}

\subsection{Characteristics of the Study Sample}

Characteristics of the study sample are presented in Table 1 . The study covered more women than men (67\%), mostly the respondents in the age category between 30-49 years (76\%), with a lower educational level $(60 \%)$ and unemployed (58\%). Most of the participants described their health state as fair or rather fair $(65 \%)$. About $37 \%$ of the beneficiaries of government welfare assistance declared a smoking status. Additionally, the proportion of the participants who did not follow recommendations related to a healthy diet $(90 \%)$, recreational physical activity $(74 \%)$, or BMI $(58 \%)$ was high. As a consequence, the combined healthy lifestyle index equal 0 (which means that all four lifestyle-related recommendations were not followed) was observed in $18 \%$ of the study sample and equal 1 (which means that only 1 recommendation was followed) in $40 \%$ of the participants. Only 18 individuals $(1.1 \%)$ received the maximum number of points for a combined healthy lifestyle index.

\subsection{Correlates of not Following Recommendations for Alcohol Consumption}

About $42 \%$ of the participants, including $67 \%$ of the men and $30 \%$ of the women, exceeded the recommended level for alcohol consumption (Table 1). In the adjusted model, the men tended not to follow recommendations for alcohol consumption more frequently than the women ( $\mathrm{OR}=4.5, p<0.001$ ) (Table 2). The higher odds of not following alcohol-related recommendations was also observed for the subjects declaring having a permanent or temporary job compared to the unemployed participants $(\mathrm{OR}=1.2, p=0.04)$. A lower combined healthy lifestyle index was associated with not following recommendations for alcohol consumption ( $\mathrm{OR}=1.1, p=0.04)$. In other words, the individuals who declared no healthy lifestyle-related behaviour (regarding a diet, BMI, physical activity, and smoking) at the same time did not comply with the recommendations on alcohol consumption. Table S1 presents results of the analyses stratified by gender. Only the men who declared absence of the children below 15 years of age in the household consumed alcohol at the level exciding the existing recommendations more frequently than those having children $(\mathrm{OR}=1.5, p=0.06)$. 
Table 1. Characteristics of the study population.

\begin{tabular}{|c|c|c|c|c|c|c|}
\hline \multirow[b]{2}{*}{ Variables } & \multirow[b]{2}{*}{$\begin{array}{c}\text { Total * } \\
n=1644 \\
100 \%\end{array}$} & \multicolumn{2}{|c|}{ Men $n=545(33.2 \%)$} & \multicolumn{2}{|c|}{ Women $n=1099(66.8 \%)$} & \multirow[t]{2}{*}{$p^{* *}$} \\
\hline & & $\begin{array}{l}\text { Total } \\
n(\%)\end{array}$ & $\begin{array}{c}\text { Not Following } \\
\text { Alcohol-Related } \\
\text { Recommendations } \\
n=364(66.8 \%)\end{array}$ & $\begin{array}{l}\text { Total } \\
n(\%)\end{array}$ & $\begin{array}{c}\text { Not Following } \\
\text { Alcohol-Related } \\
\text { Recommendations } \\
n=330(30.0 \%)\end{array}$ & \\
\hline \multicolumn{7}{|l|}{ Age (years) } \\
\hline$<30$ & $181(11.0 \%)$ & $42(23.2 \%)$ & $28(66.7 \%)$ & $139(76.8 \%)$ & $46(33.1 \%)$ & $p<0.001$ \\
\hline $30-39$ & $700(42.6 \%)$ & $195(27.9 \%)$ & $134(68.7 \%)$ & $505(72.1 \%)$ & $148(29.3 \%)$ & $p<0.001$ \\
\hline $40-49$ & $557(33.9 \%)$ & $203(36.4 \%)$ & $133(65.5 \%)$ & $354(63.6 \%)$ & $102(28.8 \%)$ & $p<0.001$ \\
\hline $50-59$ & $206(12.5 \%)$ & $105(51.0 \%)$ & $69(65.7 \%)$ & $101(49.0 \%)$ & $34(33.7 \%)$ & $p<0.001$ \\
\hline \multicolumn{7}{|l|}{ Education } \\
\hline Primary & $443(27.0 \%)$ & $191(43.1 \%)$ & $132(69.1 \%)$ & $252(56.9 \%)$ & $77(30.6 \%)$ & $p<0.001$ \\
\hline Vocational & $549(33.4 \%)$ & $221(40.3 \%)$ & $139(62.9 \%)$ & $328(59.7 \%)$ & $104(31.7 \%)$ & $p<0.001$ \\
\hline Secondary & $562(34.2 \%)$ & $125(22.2 \%)$ & $87(69.6 \%)$ & $437(77.8 \%)$ & $115(26.3 \%)$ & $p<0.001$ \\
\hline High & $90(5.4 \%)$ & $8(8.9 \%)$ & $6(75.0 \%)$ & $82(91.1 \%)$ & $34(41.5 \%)$ & $p>0.05$ \\
\hline \multicolumn{7}{|l|}{ Employment status } \\
\hline Permanent job & $492(29.9 \%)$ & $210(42.7 \%)$ & $142(67.6 \%)$ & $282(57.3 \%)$ & $83(29.4 \%)$ & $p<0.001$ \\
\hline Temporary job & $140(8.5 \%)$ & $64(45.7 \%)$ & $51(79.7 \%)$ & $76(54.3 \%)$ & $29(38.2 \%)$ & $p<0.001$ \\
\hline Disabled or retired & $53(3.2 \%)$ & $27(50.9 \%)$ & $14(51.9 \%)$ & $26(49.1 \%)$ & $9(34.6 \%)$ & $p>0.05$ \\
\hline Unemployed & $959(58.3 \%)$ & $244(25.4 \%)$ & $157(64.3 \%)$ & $715(74.6 \%)$ & $209(29.2 \%)$ & $p<0.001$ \\
\hline \multicolumn{7}{|l|}{$\begin{array}{l}\text { Subjective assessment of } \\
\text { monthly income }\end{array}$} \\
\hline $\begin{array}{l}\text { Sufficient to cover all living needs plus } \\
\text { may save a certain amount }\end{array}$ & $19(1.2 \%)$ & $4(21.1 \%)$ & $4(100.0 \%)$ & $15(78.9 \%)$ & $6(40.0 \%)$ & $p=0.05$ \\
\hline Sufficient to cover all living needs & $182(11.1 \%)$ & $52(28.6 \%)$ & $35(67.3 \%)$ & $130(71.4 \%)$ & $39(30.0 \%)$ & $p<0.001$ \\
\hline Sufficient to cover basic needs only & $867(52.7 \%)$ & $267(30.8 \%)$ & $175(65.5 \%)$ & $600(69.2 \%)$ & $172(28.7 \%)$ & $p<0.001$ \\
\hline Not sufficient to cover even basic needs & $411(25.0 \%)$ & $173(42.1 \%)$ & $121(69.9 \%)$ & $238(57.9 \%)$ & $84(35.3 \%)$ & $p<0.001$ \\
\hline Difficult to say & $165(10.0 \%)$ & $49(29.7 \%)$ & $29(59.2 \%)$ & $116(70.3 \%)$ & $29(25.0 \%)$ & $p<0.001$ \\
\hline \multicolumn{7}{|l|}{$\begin{array}{l}\text { Subjective assessment of living } \\
\text { conditions }\end{array}$} \\
\hline Fair or rather fair & $763(46.4 \%)$ & $223(29.2 \%)$ & $138(61.9 \%)$ & $540(70.8 \%)$ & $157(29.1 \%)$ & $p<0.001$ \\
\hline Neither fair nor poor & $744(45.3 \%)$ & $272(36.6 \%)$ & $190(69.9 \%)$ & $472(63.4 \%)$ & $147(31.1 \%)$ & $p<0.001$ \\
\hline Rather poor & $79(4.8 \%)$ & $27(34.2 \%)$ & $22(81.5 \%)$ & $52(65.8 \%)$ & $16(30.8 \%)$ & $p<0.001$ \\
\hline Very poor & $26(1.6 \%)$ & $13(50.0 \%)$ & $8(61.5 \%)$ & $13(50.0 \%)$ & $6(46.2 \%)$ & $p>0.05$ \\
\hline Difficult to say & $32(2.0 \%)$ & $10(31.3 \%)$ & $6(60.0 \%)$ & $22(68.8 \%)$ & $4(18.2 \%)$ & $p<0.03$ \\
\hline
\end{tabular}


Table 1. Cont.

\begin{tabular}{|c|c|c|c|c|c|c|}
\hline \multirow[b]{2}{*}{ Variables } & \multirow[b]{2}{*}{$\begin{array}{c}\text { Total * } \\
n=1644 \\
100 \%\end{array}$} & \multicolumn{2}{|c|}{ Men $n=545(33.2 \%)$} & \multicolumn{2}{|c|}{ Women $n=1099(66.8 \%)$} & \multirow[t]{2}{*}{$p^{* *}$} \\
\hline & & $\begin{array}{l}\text { Total } \\
n(\%)\end{array}$ & $\begin{array}{c}\text { Not Following } \\
\text { Alcohol-Related } \\
\text { Recommendations } \\
n=364(66.8 \%)\end{array}$ & $\begin{array}{l}\text { Total } \\
n(\%)\end{array}$ & $\begin{array}{c}\text { Not Following } \\
\text { Alcohol-Related } \\
\text { Recommendations } \\
n=330(30.0 \%)\end{array}$ & \\
\hline \multicolumn{7}{|l|}{$\begin{array}{l}\text { Cohabitation with partner } \\
\text { and/or family }\end{array}$} \\
\hline Yes & $1389(84.5 \%)$ & $462(33.3 \%)$ & $303(65.6 \%)$ & $927(66.7 \%)$ & $270(29.1 \%)$ & $p<0.001$ \\
\hline No & $255(15.5 \%)$ & $83(32.6 \%)$ & $61(73.5 \%)$ & $172(67.4 \%)$ & $60(34.9 \%)$ & $p<0.001$ \\
\hline \multicolumn{7}{|l|}{ Children $<15$ years } \\
\hline Yes & $1112(67.6 \%)$ & $366(32.9 \%)$ & $234(63.9 \%)$ & $746(67.1 \%)$ & $216(28.9 \%)$ & $p<0.001$ \\
\hline No & $532(32.4 \%)$ & $179(33.6 \%)$ & $130(72.6 \%)$ & $353(66.4 \%)$ & $114(32.3 \%)$ & $p<0.001$ \\
\hline \multicolumn{7}{|l|}{$\begin{array}{l}\text { Subjective assessment of life } \\
\text { satisfaction }\end{array}$} \\
\hline Extremely satisfied or satisfied & $678(41.2 \%)$ & $207(30.5 \%)$ & $131(63.3 \%)$ & $471(69.5 \%)$ & $133(28.2 \%)$ & $p<0.001$ \\
\hline Neutral & $819(49.8 \%)$ & $276(33.7 \%)$ & $193(69.9 \%)$ & $543(66.3 \%)$ & $166(30.6 \%)$ & $p<0.001$ \\
\hline Slightly dissatisfied & $101(6.1 \%)$ & $38(37.6 \%)$ & $25(65.8 \%)$ & $63(62.4 \%)$ & $22(34.9 \%)$ & $p<0.003$ \\
\hline Dissatisfied or extremely dissatisfied & $46(2.8 \%)$ & $24(52.2 \%)$ & $15(62.5 \%)$ & $22(47.8 \%)$ & $9(40.9 \%)$ & $p>0.05$ \\
\hline \multicolumn{7}{|l|}{ Subjective health state } \\
\hline Fair/rather fair & $1075(65.4 \%)$ & $323(30.0 \%)$ & $224(69.4 \%)$ & $752(70.0 \%)$ & $228(30.3 \%)$ & $p<0.001$ \\
\hline Neither fair nor poor & $393(23.9 \%)$ & $141(35.9 \%)$ & $88(62.4 \%)$ & $252(64.1 \%)$ & $71(28.2 \%)$ & $p<0.001$ \\
\hline Rather poor/poor & $176(10.7 \%)$ & $81(46.0 \%)$ & $52(64.2 \%)$ & $95(54.0 \%)$ & $31(32.6 \%)$ & $p<0.001$ \\
\hline \multicolumn{7}{|l|}{ Number of health problems } \\
\hline 0 & $221(13.7 \%)$ & $99(44.8 \%)$ & $62(62.6 \%)$ & $122(55.2 \%)$ & $33(27.0 \%)$ & $p<0.001$ \\
\hline $1-3$ & $863(53.6 \%)$ & $297(34.4 \%)$ & $204(68.7 \%)$ & $566(65.6 \%)$ & $169(29.9 \%)$ & $p<0.001$ \\
\hline $4-6$ & $432(26.8 \%)$ & $115(26.6 \%)$ & $76(66.1 \%)$ & $317(73.4 \%)$ & $93(29.3 \%)$ & $p<0.001$ \\
\hline$\geq 7$ & $95(5.9 \%)$ & $27(28.4 \%)$ & $17(63.0 \%)$ & $68(71.6 \%)$ & $23(33.8 \%)$ & $p<0.01$ \\
\hline \multicolumn{7}{|l|}{$\begin{array}{l}\text { Following smoking-related } \\
\text { recommendations }\end{array}$} \\
\hline Yes & $1039(63.3 \%)$ & $259(24.9 \%)$ & $165(63.7 \%)$ & $780(75.1 \%)$ & $214(27.4 \%)$ & $p<0.001$ \\
\hline No & $603(36.7 \%)$ & $285(47.3 \%)$ & $198(69.5 \%)$ & $318(52.7 \%)$ & $115(36.2 \%)$ & $p<0.001$ \\
\hline
\end{tabular}


Table 1. Cont.

\begin{tabular}{|c|c|c|c|c|c|c|}
\hline \multirow[b]{2}{*}{ Variables } & \multirow[b]{2}{*}{$\begin{array}{c}\text { Total * } \\
n=1644 \\
100 \%\end{array}$} & \multicolumn{2}{|c|}{ Men $n=545(33.2 \%)$} & \multicolumn{2}{|c|}{ Women $n=1099(66.8 \%)$} & \multirow[t]{2}{*}{$p^{* *}$} \\
\hline & & $\begin{array}{l}\text { Total } \\
n(\%)\end{array}$ & $\begin{array}{c}\text { Not Following } \\
\text { Alcohol-Related } \\
\text { Recommendations } \\
n=364(66.8 \%)\end{array}$ & $\begin{array}{l}\text { Total } \\
n(\%)\end{array}$ & $\begin{array}{c}\text { Not Following } \\
\text { Alcohol-Related } \\
\text { Recommendations } \\
n=330(30.0 \%)\end{array}$ & \\
\hline \multicolumn{7}{|c|}{$\begin{array}{l}\text { Following diet-related } \\
\text { recommendations }\end{array}$} \\
\hline Yes & $157(9.6 \%)$ & $43(27.4 \%)$ & $30(69.8 \%)$ & $114(72.6 \%)$ & $30(26.3 \%)$ & $p<0.001$ \\
\hline No & $1487(90.4 \%)$ & $502(33.8 \%)$ & $334(66.5 \%)$ & $985(66.2 \%)$ & $300(30.5 \%)$ & $p<0.001$ \\
\hline \multicolumn{7}{|c|}{$\begin{array}{l}\text { Following recommendations related to } \\
\text { recreational physical activity }\end{array}$} \\
\hline Yes & $424(26.2 \%)$ & $135(31.8 \%)$ & $90(66.7 \%)$ & $289(68.2 \%)$ & $84(29.1 \%)$ & $p<0.001$ \\
\hline No & $1194(73.8 \%)$ & $402(33.7 \%)$ & $268(66.7 \%)$ & $792(66.3 \%)$ & $238(30.1 \%)$ & $p<0.001$ \\
\hline \multicolumn{7}{|c|}{$\begin{array}{l}\text { Following BMI related } \\
\text { recommendations }\end{array}$} \\
\hline Yes & $697(42.4 \%)$ & $196(28.1 \%)$ & $138(70.4 \%)$ & $501(71.9 \%)$ & $148(29.5 \%)$ & $p<0.001$ \\
\hline No & $947(57.6 \%)$ & $349(36.8 \%)$ & $226(64.8 \%)$ & $598(63.2 \%)$ & $182(30.4 \%)$ & $p<0.001$ \\
\hline \multicolumn{7}{|c|}{ Combined HLI } \\
\hline 0 & $291(18.0 \%)$ & $144(49.5 \%)$ & $102(70.8 \%)$ & $147(50.5 \%)$ & $52(35.4 \%)$ & $p<0.001$ \\
\hline 1 & $646(40.0 \%)$ & $210(32.5 \%)$ & $131(62.4 \%)$ & $436(67.5 \%)$ & $133(30.5 \%)$ & $p<0.001$ \\
\hline 2 & $406(25.1 \%)$ & $128(31.5 \%)$ & $83(64.8 \%)$ & $278(68.5 \%)$ & $81(29.1 \%)$ & $p<0.001$ \\
\hline 3 & $255(15.8 \%)$ & $51(20.0 \%)$ & $39(76.5 \%)$ & $204(80.0 \%)$ & $50(24.5 \%)$ & $p<0.001$ \\
\hline 4 & $18(1.1 \%)$ & $3(16.7 \%)$ & $2(66.7 \%)$ & $15(83.3 \%)$ & $5(33.3 \%)$ & $p>0.05$ \\
\hline
\end{tabular}

* The numbers might not sum up to the total sample as some missing data could occur. ${ }^{* *}$ Men vs. women not following alcohol-related recommendations. $p$-values was calculated using the test for equality of two fractions. HLI-Healthy Lifestyle Index (as the sum of points given for each of the four lifestyle-related factors (smoking, BMI, diet, and recreational physical activity). Participants received 1 if they followed the relevant recommendations and 0 if the recommendations were not followed). BMI—Body Mass Index. 
Table 2. Odds ratio (OR) and 95\% confidence interval (CI) for not following recommendations for alcohol consumption by socio-demographic and lifestyle-related characteristics of the population.

\begin{tabular}{|c|c|c|c|c|}
\hline \multirow{2}{*}{ Variables } & \multicolumn{2}{|c|}{ Unadjusted Model } & \multicolumn{2}{|c|}{ Adjusted Model } \\
\hline & OR $(95 \% \mathrm{CI})$ & $p$ & OR $(95 \% \mathrm{CI})$ & $p$ \\
\hline \multicolumn{5}{|l|}{ Sex } \\
\hline Man & $4.69(3.76-5.84)$ & $<0.001$ & $4.49(3.52-5.68)$ & $<0.001$ \\
\hline Women & 1 & & 1 & \\
\hline \multicolumn{5}{|l|}{ Age (years) } \\
\hline$<30$ & 1 & & 1 & \\
\hline $30-39$ & $0.98(0.70-1.36)$ & 0.88 & $0.88(0.61-1.27)$ & 0.50 \\
\hline $40-49$ & $1.03(0.75-1.48)$ & 0.76 & $0.78(0.53-1.14)$ & 0.20 \\
\hline $50-59$ & $1.45(0.97-2.16)$ & 0.07 & $0.84(0.53-1.14)$ & 0.45 \\
\hline \multicolumn{5}{|l|}{ Education } \\
\hline Primary & $1.51(1.18-1.93)$ & $<0.001$ & $1.03(0.77-1.37)$ & 0.85 \\
\hline Vocational & $1.35(1.07-1.70)$ & 0.01 & $0.99(0.76-1.29)$ & 0.93 \\
\hline Secondary or higher & 1 & & 1 & \\
\hline \multicolumn{5}{|l|}{ Employment status } \\
\hline Permanent or temporary job & $1.51(1.23-1.85)$ & $<0.001$ & $1.23(1.01-1.63)$ & 0.04 \\
\hline Disabled or retired & $1.24(0.71-2.17)$ & 0.45 & $0.88(0.48-1.63)$ & 0.69 \\
\hline Unemployed & 1 & & 1 & \\
\hline \multicolumn{5}{|l|}{ Subjective assessment of monthly income } \\
\hline Sufficient to cover all living needs & 1 & & 1 & \\
\hline Sufficient to cover basic needs only & $0.93(0.68-1.27)$ & 0.65 & $0.98(0.73-1.33)$ & 0.68 \\
\hline Not sufficient to cover even the basic needs & $1.39(0.99-1.95)$ & 0.06 & $1.05(0.78-1.65)$ & 0.30 \\
\hline Difficult to say & $0.76(0.49-1.15)$ & 0.20 & $0.69(0.43-1.11)$ & 0.13 \\
\hline \multicolumn{5}{|l|}{$\begin{array}{l}\text { Subjective assessment of living } \\
\text { conditions }\end{array}$} \\
\hline Fair or rather fair & 1 & & 1 & \\
\hline Neither fair nor poor or difficult to say & $1.28(1.05-1.57)$ & 0.02 & $1.13(0.89-1.45)$ & 0.32 \\
\hline Rather poor or very poor & $1.56(1.03-2.34)$ & 0.03 & $1.35(0.82-2.21)$ & 0.23 \\
\hline Cohabitation with partner and/or family & 1 & & 1 & \\
\hline Yes & 1 & & 1 & \\
\hline No & $1.29(0.98-1.68)$ & 0.07 & $1.22(0.84-1.77)$ & 0.31 \\
\hline \multicolumn{5}{|l|}{ Children $<15$ years } \\
\hline Yes & 1 & & 1 & \\
\hline No & $1.25(1.02-1.54)$ & 0.04 & $1.13(0.85-1.52)$ & 0.40 \\
\hline \multicolumn{5}{|l|}{ Subjective assessment of life satisfaction } \\
\hline Extremely satisfied/satisfied & 1 & & 1 & \\
\hline Neutral & $1.22(0.99-1.51)$ & 0.06 & $1.10(0.86-1.42)$ & 0.45 \\
\hline Slightly dissatisfied & $1.36(0.90-2.08)$ & 0.15 & $1.07(0.65-1.77)$ & 0.80 \\
\hline Dissatisfied/extremely dissatisfied & $1.72(0.94-3.11)$ & 0.08 & $1.06(0.53-2.13)$ & 0.87 \\
\hline \multicolumn{5}{|l|}{ Subjective health state } \\
\hline Fair/rather fair & 1 & & & \\
\hline Neither fair nor poor & $0.94(0.74-1.18)$ & 0.58 & & \\
\hline Rather poor/poor & $1.23(0.89-1.69)$ & 0.20 & & \\
\hline \multicolumn{5}{|l|}{ Number of health problems } \\
\hline 0 & $1.04(0.64-1.69)$ & 0.52 & & \\
\hline $1-3$ & $1.05(0.68-1.61)$ & 0.47 & & \\
\hline $4-6$ & $0.88(0.56-1.39)$ & 0.33 & & \\
\hline$\geq 7$ & 1 & & & \\
\hline \multicolumn{5}{|l|}{ Combined HLI } \\
\hline $0-2$ & $1.41(1.08-1.85)$ & 0.01 & $1.11(1.01-1.49)$ & 0.04 \\
\hline $3-4$ & 1 & & 1 & \\
\hline
\end{tabular}




\section{Discussion}

Our study indicates that, even in a rather homogenous population of government welfare assistance beneficiaries from one region of Poland, some differences in alcohol consumption exist. Higher odds of not following recommendations for alcohol consumption was observed among the men, subjects declaring having a permanent or a temporary job, and those with other unfavorable lifestyle-related factors. These results are crucial for the development of effective interventions that take into consideration specific needs of disadvantaged individuals.

Our analyses indicate that about $42 \%$ of the beneficiaries of government welfare assistance, including $67 \%$ of the men and $30 \%$ of the women, exceeded the recommended level of alcohol consumption. An advantage of the selected approach to evaluate if the study subjects followed alcohol-related recommendations (as a complex indicator) as compared to evaluating drinking status, average volume of alcohol consumption, or binge drinking separately, is that, this way, we have a full picture of an individual's drinking pattern. However, such an approach limits direct comparison of the level of alcohol consumption in our study with that of the general population in Poland or with data from other countries. The existing analyses indicate that alcohol consumption in Poland has remained at a level close to the average consumption in Europe. However, higher prevalence of alcohol drinking can be observed among disadvantaged groups [3]. Binge drinking or heavy episodic drinking (HED), usually defined as drinking at least $60 \mathrm{~g}$ or more of pure alcohol on at least one occasion at least once per month (which equals to 5 or more drinks per occasion at least once per month as selected in the current study), is of specific concern considering its public health and clinical consequences $[3,21]$. In our study, binge drinking (yes/no) was considered as one of the components of the selected indicator of following alcohol-related recommendations. In the high-income countries, it is common that poorer people are more likely to be abstainers than richer people and that those less affluent, on average, drink less frequently than the more affluent individuals [3,11,26-28]. However, HED is more common in poorer societies $[3,11,27]$.

One traditional differentiation in alcohol consumption, also observed in our study, has been pointed out with regard to sex. Men generally drink considerably more alcohol than women, in terms of frequency and the volume of drinking [29]. Within a given society, sex differentiation is often greater among poorer people than among the richer ones [3]. Burden of alcohol-attributable diseases also varies by sex (with men at a higher risk than women) [3]. This can be explained by different drinking patterns (as described above) and by the fact that men are usually representing other risky behaviours (tobacco smoking, unhealthy diet, and obesity) more frequently than women [3,30-33].

We found higher odds of not following recommendations related to alcohol consumption for the subjects declaring having a permanent or a temporary job compared to those unemployed ones. In general, the study population is a socially disadvantaged population. However, within this group, some part of the participants was employed (with a salary not exceeding minimum income stated by The Social Welfare Act to be able to receive social aid). It needs to be pointed out that the educational level of the study participants was much lower than that of the general population in Poland (as an example, higher education was indicated by $5.4 \%$ of the study participants, whereas, based on a Demographic Yearbook of Poland, 2016, 24.3\% Poles represented a higher educational level) [34]. Moreover, when considering characteristics of the district (more than $90 \%$ of its residents representing rural areas), the majority of people declaring having a permanent or temporary job were working in agriculture or related professions and were mostly blue-collar workers [15-17]. A study that examined the relationship between country-level characteristics and individual socio-economic status (SES), and individual alcohol consumption in 33 countries, has shown that, for both sexes and all countries, higher individual SES was positively associated with their drinking status [10]. In many societies, access to alcoholic beverages is greater for those representing a more affluent status or among employed individuals $[3,35,36]$. Higher percentages of risky drinking observed among the people with a permanent or a temporary job in our study as compared to the unemployed ones can be interpreted by the amount of money that the participants needed to have to be able to spend it on 
alcohol. The existing studies point out that risky drinking is often more prevalent among blue-collar workers [3]. Moreover, alcohol consumption can be influenced by job/workplace characteristics, including employee dissatisfaction, workplace control, and workplace culture [5,37-43]. However, this was not evaluated in the current study. It can be a subject of more in-depth analyses in the future.

Our analyses indicate that the individuals who declared unhealthy lifestyle-related behaviours at the same time did not comply with recommendations on alcohol consumption. Other studies have also found similar associations, suggesting the potential for clustering behaviours acting synergistically toward individual health $[1,44,45]$. As an example, in the study by Sandoval et al., high health conscious individuals (representing those with a high health consciousness index based on dietary habits, physical activity, and smoking status) including both men and women were less likely to consume alcohol regularly and engage in HED [44].

Individuals with low SES experience disproportionately greater alcohol-attributable health consequences than individuals with high SES [1]. Differential alcohol use patterns, vulnerability, presence of other lifestyle-related factors, and access to healthcare or interventional facilities among socio-economic groups can explain socio-economic inequalities in alcohol-related harm $[1,9,10,12,46-48]$.

Alcohol consumption as one of the main factors for death, disease, and disability has substantial financial burden on a society, with economic costs ranging from $1.3 \%$ to $3.3 \%$ of the gross domestic product in the middle-income and high-income countries [49]. Thus, effective interventions tailored to the specific needs represented by a society are crucial for changing the existing prevalence and patterns of alcohol use. The existing studies point out that initiatives addressing neighborhood planning, zoning, and licensing are among the most effective approaches toward reducing socio-economic inequalities in alcohol consumption [5]. Minimum unit pricing has been indicated as such a strategy, which should mostly affect heavy drinkers [50,51]. Additionally, screening and brief intervention have been shown to be an effective approach to identify and reduce risky alcohol use [52,53]. Interventions should not only focus on alcohol consumption but also on other lifestyle-related factors. They should eliminate smoking and promote a healthy diet, recreational physical activity, or recommended BMI. Given that individuals with low SES are less likely to utilize primary care services, equal access to screening and intervention facilities would be a prerequisite for a strategy to reduce socio-economic inequalities [1].

The current analyses were conducted among socially-disadvantaged adults, which constitutes the major strength of the study. To the best of our knowledge, such comprehensive analyses have been performed for the first time among such vulnerable populations in Poland. Other advantages of this study are related to a medium-to-large sample size, the substantial participation rate, and face-to-face interviews selected to obtain relevant data. As pointed out above, another strength of this study is related to the fact that we have assessed correlates of not following alcohol-related recommendations (in one indicator we considered the level and pattern of alcohol consumption), whereas other studies rely mostly on a single indicator (volume of alcohol or frequency of drinking or HED).

The limited generalizability of the findings needs to mentioned (as the study was conducted among social assistance beneficiaries from a socio-economically disadvantaged rural area in Poland). Additionally, a complex indicator of alcohol consumption may limit direct comparisons with other studies in this field. Moreover, causality cannot be inferred due to the cross-sectional nature of the current study. Finally, measurement of alcohol use is also a potential limitation of the presented analyses since some underreporting could occur.

\section{Conclusions}

Our study indicates that being men, having a permanent or a temporary job, and coexistence of other unfavorable lifestyle-related factors are important correlates of not following recommendations for alcohol consumption among beneficiaries of government welfare assistance. There is still a need for in-depth studies on the factors influencing decisions related to alcohol consumption among socially-disadvantaged individuals. Considering not fully conclusive results, more research should focus on the employment status as a correlate of unhealthy alcohol use as well as going beyond 
available financial resources to buy such products. With this regard, workplace characteristics and social functioning should be an urgent interest.

Taking into account that high proportion of this vulnerable population does not follow existing recommendations, development and implementation of effective interventions aimed at reduction of alcohol consumption is still a necessity. Nevertheless, because of a complex and diverse nature of social determinants that have an influence on different populations, it is impossible to point to one strategy that could result in a reduction of alcohol consumption and relate to it adverse effects on a community-wide basis. Therefore, it is vital to use the most relevant and reliable information to elaborate a set of measures that would be best for individual groups and specific settings. To do that, we have to understand the ways in which alcohol negatively influences various groups. Additionally, since unfavourable lifestyle factors coexist and affect alcohol consumption, interventions to address them are necessary.

Supplementary Materials: The following are available online at http://www.mdpi.com/1660-4601/17/23/9074/s1, Table S1. Odds ratio (OR) and $95 \%$ confidence interval (CI) for not following recommendations for alcohol consumption by socio-demographic and lifestyle-related characteristics of the population-analysis stratify by gender.

Author Contributions: D.K. and K.P. conceived the original idea for the analysis, participated in the statistical analyses and interpretation of the results, co-drafted the manuscript, and contributed to the final version of the manuscript. D.K. was the Principal Investigator of the project PL13-27/032/13/NMF/2015/00/2802/678. All authors provided substantial intellectual contributions and approved the final version of manuscript.

Funding: This research was funded by a grant from Norway through the Norway Grants and co-financed by the Polish state budget grant number: PL13-27/032/13/NMF/2015/00/2802/678. Written permission has been provided for the data use. The funding body had no role in the design of the study and collection, analysis, and interpretation of the data and in writing the manuscript.

Conflicts of Interest: The authors declare no conflict of interest.

\section{References}

1. Probst, C.; Kilian, C.; Sanchez, S.; Lange, S.; Rehm, J. The role of alcohol use and drinking patterns in socioeconomic inequalities in mortality: A systematic review. Lancet Public Health 2020, 5, e324-e332. [CrossRef]

2. UN. Transforming our World: The 2030 Agenda for Sustainable Development. 2015. Available online: https://sdgs.un.org/goals/ (accessed on 10 October 2020).

3. World Health Organization. Global Status Report on Alcohol and Health; World Health Organization: Geneva, Switzerland, 2018.

4. Collin, J.; Casswell, S. Alcohol and the Sustainable Development Goals-Major Obstacle to Development. 2018. Available online: https://iogt.org/wp-content/uploads/2015/03/Alcohol-and-SDGs_new.pdf (accessed on 2 October 2019).

5. Roche, A.; Kostadinov, V.; Fischer, J.; Nicholas, R.; O'Rourke, K.; Pidd, K.; Trifonoff, A. Addressing inequities in alcohol consumption and related harms. Health Promot Int. 2015, 30 (Suppl. 2), 20-35. [CrossRef] [PubMed]

6. Collins, S.E. Associations Between Socioeconomic Factors and Alcohol Outcomes. Alcohol. Res. 2016, 38, 83-94. [PubMed]

7. Probst, C.; Roerecke, M.; Behrendt, S.; Rehm, J. Socioeconomic differences in alcohol-attributable mortality compared with all-cause mortality: A systematic review and meta-analysis. Int. J. Epidemiol. 2014, 43, 1314-1327. [CrossRef] [PubMed]

8. Probst, C.; Roerecke, M.; Behrendt, S.; Rehm, J. Gender differences in socioeconomic inequality of alcohol-attributable mortality: A systematic review and meta-analysis. Drug Alcohol. Rev. 2015, 34, 267-277. [CrossRef] [PubMed]

9. Jones, L.; Bates, G.; McCoy, E.; Bellis, M.A. Relationship between alcohol-attributable disease and socioeconomic status, and the role of alcohol consumption in this relationship: A systematic review and meta-analysis. BMC Public Health 2015, 18, 400. [CrossRef] 
10. Grittner, U.; Kuntsche, S.; Gmel, G.; Bloomfield, K. Alcohol consumption and social inequality at the individual and country levels—results from an international study. Eur. J. Public Health 2013, 23, 332-339. [CrossRef]

11. Bloomfield, K.; Grittner, U.; Kramer, S.; Gmel, G. Social inequalities in alcohol consumption and alcohol-related problems in the study countries of the EU concerted action 'Gender, Culture and Alcohol Problems: A Multi-national Study’. Alcohol. Alcohol. Suppl. 2006, 41, i26-i36. [CrossRef]

12. Bellis, M.A.; Hughes, K.; Nicholls, J.; Sheron, N.; Gilmore, I.; Jones, L. The alcohol harm paradox: Using a national survey to explore how alcohol may disproportionately impact health in deprived individuals. BMC Public Health 2016, 16, 111. [CrossRef]

13. Morley, K.C.; Logge, W.; Pearson, S.A.; Baillie, A.; Haber, P.S. Socioeconomic and geographic disparities in access to pharmacotherapy for alcohol dependence. J. Subst Abuse Treat. 2017, 74, 23-25. [CrossRef]

14. Nyaronga, D.; Greenfield, T.K.; McDaniel, P.A. Drinking context and drinking problems among black, white, and Hispanic men and women in the 1984, 1995, and 2005 U.S. National Alcohol Surveys. J. Stud. Alcohol. Drugs 2009, 70, 16-26. [CrossRef] [PubMed]

15. Milcarz, K.; Makowiec-Dabrowska, T.; Bąk-Romaniszyn, L.; Kaleta, D. Smoking Patterns and Smoking Cessation Willingness-A Study among Beneficiaries of Government Welfare Assistance in Poland. Int. J. Environ. Res. Public Health 2017, 14, 131. [CrossRef] [PubMed]

16. Kałucka, S.; Kaleta, D.; Makowiec-Dabrowska, T. Prevalence of Dietary Behavior and Determinants of Quality of Diet among Beneficiaries of Government Welfare Assistance in Poland. Int. J. Environ. Res. Public Health 2019, 16, 501. [CrossRef] [PubMed]

17. Kaleta, D.; Kałucka, S.; Szatko, F.; Makowiec-Dąbrowska, T. Prevalence and Correlates of Physical Inactivity during Leisure-Time and Commuting among Beneficiaries of Government Welfare Assistance in Poland. Int. J. Environ. Res. Public Health 2017, 14, 1126. [CrossRef] [PubMed]

18. The Social Welfare Act on 12 of March 2004. Available online: http://isap.sejm.gov.pl/isap.nsf/DocDetails. xsp?id=WDU20040640593 (accessed on 10 November 2020).

19. Central Statistical Office. Beneficiaries of Social Assistance and Family Benefits in 2014; The Statistical Office: Krakow, Poland, 2015.

20. Lenz, T.L.; Gillespie, N.D.; Skradski, J.; Viereck, L.K.; Packard, K.A.; Monaghan, M.S. Development of a composite lifestyle index and its relationship to quality of life improvement: The CLI pilot study. ISRN Prev. Med. 2013, 2013, 1-7. [CrossRef] [PubMed]

21. World Health Organization. WHO Publication No. WHO/MSD/MSB/00, 4, 2000. Department of Mental Health and Substance Abuse. In International guide for Monitoring Alcohol Consumption and Related Harm; World Health Organization: Geneva, Switzerland, 2000.

22. Znyk, M.; Polańska, K.; Bąk-Romaniszyn, L.; Kaleta, D. Correlates of Blood Pressure and Cholesterol Level Testing Among a Socially-Disadvantaged Population in Poland. Int. J. Environ. Res. Public Health 2020, 17, 2123. [CrossRef] [PubMed]

23. Body Mass Index. Available online: http:/www.euro.who.int/en/health-topics/disease-prevention/nutrition/ a-healthy-lifestyle/body-mass-index-bmi) (accessed on 9 November 2020).

24. US Department of Health; Human Services; US Department of Agriculture. Dietary Guidelines for Americans 2005, 6th ed.; U.S. Government Printing Office: Washington, DC, USA, 2005. Available online: http://www.health.gov/ dietaryguidelines/dge2005/dge2005/document/html/chapter9.htm (accessed on 9 November 2020).

25. US Department of Health and Human Services; Office of Disease Prevention and Health Promotion. Physical Activity Guidelines for Americans. 2008. Available online: http://www.health.gov/paguidelines (accessed on 9 November 2020).

26. Probst, C.; Manthey, J.; Rehm, J. Understanding the prevalence of lifetime abstinence from alcohol: An ecological study. Drug Alcohol. Depend. 2017, 178, 126-129. [CrossRef]

27. Room, R.; Livingston, M. The distribution of customary behaviour in a population: The total consumption model and alcohol policy. Sociol. Perspect. 2017, 60, 10-22. [CrossRef]

28. Room, R.; Jernigan, D. The ambiguous role of alcohol in economic and social development. Addiction 2000, 95 (Suppl. 4), 523-535. [CrossRef]

29. Wilsnack, R.W.; Wilsnack, S.C.; Kristjanson, A.F.; Vogeltanz-Holm, N.D.; Gmel, G. Gender and alcohol consumption: Patterns from the multinational GENACIS project. Addiction 2009, 104, 1487-1500. [CrossRef] 
30. Gubner, N.R.; Delucchi, K.L.; Ramo, D.E. Associations between binge drinking frequency and tobacco use among young adults. Addict Behav. 2016, 60, 191-196. [CrossRef] [PubMed]

31. De Leon, J.; Rendon, D.M.; Baca-Garcia, E.; Aizpuru, F.; Gonzalez-Pinto, A.; Anitua, C.; Diaz, F.J. Association between smoking and alcohol use in the general population: Stable and unstable odds ratios across two years in two different countries. Alcohol Alcohol. 2007, 42, 252-257. [CrossRef] [PubMed]

32. Fawehinmi, T.O.; Ilomäki, J.; Voutilainen, S.; Kauhanen, J. Alcohol consumption and dietary patterns: The FinDrink study. PLoS ONE 2012, 7, e38607. [CrossRef] [PubMed]

33. French, M.T.; Norton, E.C.; Fang, H.; Maclean, J.C. Alcohol consumption and body weight. Health Econ. 2010, 19, 814-832. [CrossRef] [PubMed]

34. Demographic Yearbook of Poland. 2016. Available online: https://stat.gov.pl/obszary-tematyczne/rocznikistatystyczne/roczniki-statystyczne/rocznik-demograficzny-2016,3,10.html (accessed on 10 November 2020).

35. Kan, M.Y.; Lau, M. Comparing alcohol affordability in 65 cities worldwide. Drug Alcohol. Rev. 2013, 32, $19-26$. [CrossRef]

36. AIHW. 2010 National Drug Strategy Household Survey Report; Australian Institute of Health and Welfare: Canberra, Australia, 2011.

37. Trice, H.; Sonnenstuhl, W. On the construction of drinking norms in work organizations. J. Stud. Alcohol Drugs 1990, 51, 201. [CrossRef]

38. Webb, G.; Shakeshaft, A.; Sanson-Fisher, R.; Havard, A. A systematic review of workplace interventions for alcohol related problems. Addiction 2009, 104, 365-377. [CrossRef]

39. Ames, G.; Grube, J. Alcohol availability and workplace drinking: Mixed method analyses. J. Stud. Alcohol Drugs 1999, 60, 383. [CrossRef]

40. Pidd, K.R. Responding to Alcohol and Other Drug Issues in the Workplace; National Centre for Education and Training on Addiction, Flinders University: Adelaide, Australia, 2006.

41. Pidd, K.; Roche, A. Changing workplace cultures: An integrated model for the prevention and treatment of alcohol related problems. In Drugs and Public Health: Australian Perspectives on Policy and Practice; Moore, D., Dietze, P., Eds.; Oxford University Press: Melbourne, Australia, 2008.

42. Robert Wood Johnson Foundation. Exploring the Social Determinants of Health: Work, Workplaces and Health; Robert Wood Johnson Foundation: Princeton, NJ, USA, 2011.

43. Berry, J.; Pidd, K.; Roche, A.; Harrison, J. Prevalence and patterns of alcohol use in the Australian workforce: Findings from the 2001 National Drug Strategy Household Survey. Addiction 2007, 102, 1399-1410. [CrossRef]

44. Sandoval, G.A.; Monteiro, M.G.; De Pinho Campos, K.; Shield, K.; Marinho, F. Sociodemographics, lifestyle factors and health status indicators associated with alcohol consumption and related behaviours: A Brazilian population-based analysis. Public Health 2020, 178, 49-61. [CrossRef]

45. Touvier, M.; Druesne-Pecollo, N.; Kesse-Guyot, E.; Andreeva, V.A.; Galan, P.; Hercberg, S.; Latino-Martel, P. Demographic, socioeconomic, disease history, dietary and lifestyle cancer risk factors associated with alcohol consumption. Int. J. Cancer 2014, 134, 445-459. [CrossRef] [PubMed]

46. Peña, S.; Mäkelä, P.; Valdivia, G.; Helakorpi, S.; Markkula, N.; Margozzini, P.; Koskinen, S. Socioeconomic inequalities in alcohol consumption in Chile and Finland. Drug Alcohol Depend. 2017, 1, 24-30. [CrossRef] [PubMed]

47. Grittner, U.; Kuntsche, S.; Graham, K.; Bloomfield, K. Social inequalities and gender differences in the experience of alcohol-related problems. Alcohol 2012, 47, 597-605. [CrossRef] [PubMed]

48. Makela, P.; Paljarvi, T. Do consequences of a given pattern of drinking varyby socioeconomic status? A mortality and hospitalisation follow-up foralcohol-related causes of the Finnish drinking habits surveys. J. Epidemiol. Commun. Health 2008, 62, 728-733. [CrossRef] [PubMed]

49. Rehm, J.; Mathers, C.; Popova, S.; Thavorncharoensap, M.; Teerawattananon, Y.; Patra, J. Alcohol and global health 1: Global burden of disease and injury and economic cost attributable to alcohol use and alcohol-use disorders. Lancet 2009, 373, 2223-2233. [CrossRef]

50. Holmes, J.; Meng, Y.; Meier, P.S.; Brennan, A.; Angus, C.; Campbell-Burton, A.; Guo, Y.; Hill-McManus, D.; Purshouse, R.C. Effects of minimum unit pricing for alcohol on different income and socioeconomic groups: A modelling study. Lancet 2014, 383, 1655-1664. [CrossRef]

51. O'Donnell, A.; Anderson, P.; Jane-Llopis, E.; Manthey, J.; Kaner, E.; Rehm, J. Immediate impact of minimum unit pricing on alcohol purchases in Scotland: Controlled interrupted time series analysis for 2015-18. BMJ 2019, 366, 15274. [CrossRef] 
52. Anderson, P.; Chisholm, D.; Fuhr, D.C. Effectiveness and cost-effectiveness of policies and programmes to reduce the harm caused by alcohol. Lancet 2009, 373, 2234-2246. [CrossRef]

53. Carvalho, A.F.; Heilig, M.; Perez, A.; Probst, C.; Rehm, J. Alcohol use disorders. Lancet 2019, 394, 781-792. [CrossRef]

Publisher's Note: MDPI stays neutral with regard to jurisdictional claims in published maps and institutional affiliations.

(C) 2020 by the authors. Licensee MDPI, Basel, Switzerland. This article is an open access article distributed under the terms and conditions of the Creative Commons Attribution (CC BY) license (http://creativecommons.org/licenses/by/4.0/). 